\title{
The Relationship between Management Traits and the Commitment of IT Engineers to their Organizations
}

\author{
Oludotun Oni \\ University of Phoenix, Phoenix, Arizona, USA \\ dotoni@email.phoenix.edu
}

\begin{abstract}
Since the demise of the "dot-com boom", information technology (IT) engineers have been reluctant about changing jobs when these opportunities do arise. The result is unmotivated engineers reluctantly staying with their employing organizations. This paper investigates the relationship between management traits and the commitment of information technology engineers to their organizations. Fifty seven engineers participated in the study. The results showed that engineers whose managers possess high aggregate management traits display high levels of identification commitment. There was little or no relationship between aggregate management traits and compliance commitment. Respondents whose managers possess high aggregate management trait reported low intention to leave. The study also found that respondents with high levels of identification commitment have low intent to leave their respective companies, and those with high identification commitment demonstrated high levels of compliance commitment. A relationship could not be established between compliance commitment and intent to leave.
\end{abstract}

Keywords: IT engineers, management traits, traits, commitment, management, information technology, organization

\section{Introduction}

During the "dot-com boom" era, IT engineers and technical professionals were very much in demand, with multiple offers of lucrative salaries from competing employers trying to outdo each other. Even the most loyal professionals wavered and had their loyalty tested.

Things have changed since the demise of the boom. Engineers and technicians are now generally less secure and cautious about changing jobs when these opportunities do arise. Consequently, many engineers reluctantly stay with their employing organizations; however, some are dissatisfied enough to eventually make the move to a different organization (Oni, 2005). The sources of this frustration range from little or no salary increases to bad employment climate and poor management attitudes.

Material published as part of this publication, either on-line or in print, is copyrighted by the Informing Science Institute. Permission to make digital or paper copy of part or all of these works for personal or classroom use is granted without fee provided that the copies are not made or distributed for profit or commercial advantage AND that copies 1) bear this notice in full and 2) give the full citation on the first page. It is permissible to abstract these works so long as credit is given. To copy in all other cases or to republish or to post on a server or to redistribute to lists requires specific permission and payment of a fee. Contact Publisher@,InformingScience.org to request redistribution permission.
If these negative factors are properly explored, there are possibilities of reducing their impact. The theory is that if these factors are addressed, there would be fewer turnovers when employment opportunities improve. This would also be a welcome development for employers within the IT industry. 
This paper explores some factors that impact the current trend and offers suggestions on how to mitigate the problem. More specifically, this paper analyzes the relationship between management traits and the commitment of IT engineers to their employing organizations.

\section{Related Work}

A plethora of previous research has focused on technical and engineering leadership. Engineers generally do not want to be part of the management team, but they tend to have strong opinions about how managers should function to support their career goals.

The general work climate has changed from the traditional atmosphere where leaders tend to behave like dictators. Contemporary organizational leaders tend to be more relaxed, informal, experimental, and result-oriented (Mateas \& Kleiner, 1999). They note that unlike traditional companies with rigid job assignments and slow reaction to market changes, technology companies made decisions quickly in order to take advantage of new opportunities.

According to Demarco and Lister (1999), good leaders focus their energy on promoting an atmosphere that produces a cohesive team, which has positive outcomes such as increased efficiency, a strong sense of identity, a sense of elitism and low turnover. Successful computer and software companies also had structures in which creativity was encouraged and flexibility was a requirement. This type of management cultivated inspirational environment and encouraged creativity (James, 1996).

Organizational cultures that nurture limitless wealth of imagination, teamwork, and individual autonomy are favored by the current marketplace (Champy, 1995). While some IT companies go to the extent of making this a requirement, not every company has a culture that sustains this type of creative process, thereby presenting an added layer of challenge to the technical manager trying to adopt this model.

Kouzes and Posner (1995) reveal that from the follower's perspective, there are four characteristics consistent with good leaders. The survey shows that good leaders are honest, forwardlooking, inspiring, and competent. In another study, Boehnke, DiStefano, DiStefano, and Bontis (1999) concluded that the key dimensions of leadership are universal, and include behaviors such as visionary, inspiring, stimulating, coaching, and team building. Management interference is the leadership trait that most seemed to result in the downfall of a team (Taylor, Dahnke, Snyder, \& Kuether, 1996).

Rifkin, Fineman and Ruhnke (1999) position personal attributes at the base of the hierarchical framework when developing a competency model for developing technical managers. They positioned personal traits include integrity, creativity, need for accomplishment and willingness to lead others as the key factors required for job success.

Farris and Cordero (2002) conclude that cross-functional teams have replaced functional groups in many applications and that some of these teams are globally distributed. According to Parker (2003), contemporary teams are typically diverse or virtual. Virtual teams allow organizations to retain their valued workforce who may not want to relocate (Kerber \& Buono, 2004).

These virtual teams present the challenges of managing a team with different backgrounds, cultures, languages, team player styles, training and interests (Parker, 2003). Another test for virtual cross-functional leadership is that members communicate electronically and may never meet face-to-face (Parker, 2003). Virtual teams rely heavily on telecommunications and information technologies such as conference calls, e-mail and video conferencing to leverage their expertise (Kerber \& Buono, 2004). 
Another sensitive, but prevalent subject in the information technology arena is that of outsourcing. The current business environment dictates the need for external partnerships such as outsourcing to reduce cost and increase revenue (Matthews, 2004). Today, more organizations are interested in outsourcing their IT operations (Lee, Huynh, Kwok, \& Pi, 2003; Toscano \& Waddell, 2003). Outsourcing, which is often offshore, can present the same challenges as virtual teams because many outsourcing relationships span across cultural boundaries. According to Hunter (2004), the key to a successful outsourcing project is the formation of an effective team of talent across relevant areas. While the constitution of teams is very crucial, the success of teams often depends on the leadership. Team leadership is one of the main predictors of team performance because the position can influence other performance parameters (Trent, 1996).

Commitment involves the sense of attachment and loyalty by an individual (Morris, Lydka, \& O'Creevy, 1993). Commitment is the strength of employees' identification with and involvement in their organizations (Porter, Steers, Mowday, \& Boulian, 1974). Buchanan (1974) describes commitment as ".... partisan affective attachment to the goals and values of an organization, to one's roles in relation to the goals and values, and to the organization for its own sake, apart from its purely instrumental worth" (p. 53).

O'Reilly and Chatman (1986) identify psychological attachment, which is the psychological link between the individual and the organization, as a key premise in all the various commitment approaches. O'Reilly and Chatman's bases for psychological attachment are compliance (instrumental involvement for specific, extrinsic rewards); identification (involvement based on a desire for affiliation); and internalization (involvement predicated on congruence between individual and organizational values).

Employers can positively influence how their employees feel by making conscious efforts to create a work environment that practically indicates that the employee is valued (Lynch et al., 1999). Lynch et al. (1999) also identify pay as only one factor, and that employers must address fairness, quality of supervision and support for the employees' lifestyle such as flexible hours for family and time off to deal with personal interests. Good leaders focus their energy on promoting an atmosphere that produces a cohesive team, which has positive outcomes such as increased efficiency, a strong sense of identity, a sense of elitism and low turnover (Demarco \& Lister, 1999).

Many studies such as Cohen and Golan (2007) and Park and Kim (2009) have investigated the relationship between intent to quit and job satisfaction, while Bigliardi, Petroni and Dormio (2005) linked intent to quit to interpersonal relationship. However, none of these studies have specifically focused on the commitment and intent to leave of IT engineers in relation to their managers' traits.

\section{Hypotheses}

\section{Hypothesis 1 - Identification Commitment}

Identification commitment is the construct for the attitudes and behaviors that are adopted in order to gain association with a valued third party. This type of commitment is based on a desire for affiliation (O'Reilly \& Chatman, 1986), and associated with external perceptions of the organization. Identification commitment is likely to be influenced by the management traits or attributes since the manager is the primary link between the engineers and the organization.

H1. Engineers whose managers demonstrate high aggregate management traits will display high levels of identification commitment. 


\section{Hypothesis 2 - Compliance Commitment}

Compliance commitment is a psychological attachment based on extrinsic reward (O'Reilly \& Chatman, 1986). It is hypothesized that individuals whose commitment is based on this attachment will not display the positive, pro-social behaviors associated with the high levels of internalized commitment and to a lesser extent, identification commitment. In addition, they have a much lower intention of remaining as members of the organization.

Engineers whose managers demonstrate high management traits will very likely not be attached to an organization primarily based on compliance commitment.

H2. Engineers whose managers demonstrate low aggregate management traits will display highs of compliance commitment.

\section{Hypothesis 3 - Intent to Leave}

According to Purani and Sahadev (2008), intention to leave is an employee's plan of intention to quit the present job with the intention of finding another job immediately or in the near future. Intent to leave has been negatively correlated to identification commitment (O'Reilly \& Chatman, 1986). Aggregate management trait is expected to have a negative relationship with intent to leave.

H3. Engineers whose managers demonstrate high aggregate management traits will show low levels of intent to leave.

\section{Methodology}

\section{Research Design}

Quantitative data on perceived management traits were collected through a survey questionnaire and used for this research. The participants used in the study were engineers who work in the Telecommunications Services and Telephone line of business.

The questionnaires were mailed to the participants along with an explanatory invitation letter. Demographic information such as age, gender, position, years of experience and educational background were also requested in a survey cover page.

\section{Materials and Instruments}

A 39-item questionnaire was used in this study. The questions were designed to inquire about specific areas of perceived management characteristics that represent management styles and traits. The leadership traits or characteristics considered in this research are: accountability, communication skills, courage, expertise, integrity, intellect, persistence, team building and vision. The commitment dimensions considered are identification, compliance and intent to leave. A five-point Likert-type scale was developed to obtain responses to the questions, based on the nine traits and commitment dimensions. The scale ranged from 1 (strongly disagree) to 5 (strongly agree).

The management/leadership traits section of the questionnaire was adapted from the GE Leadership Effectiveness Survey (LES) (1000ventures, n.d.), which was designed to address GE values in terms of management behavior (Ulrich, 1997). The reliability of the instrument was determined using Cronbach's alpha for the items in each of the nine management traits considered in this study. This resulted in the following alphas: team building $(0.85)$, expertise $(0.76)$, initiative $(0.86)$, persistence $(0.78)$, integrity $(0.83)$, vision $(0.83)$, communication $(0.78)$, accountability $(0.66)$, and courage $(0.85)$. The alpha for the aggregate traits is 0.95 . These values indicate 
strong internal consistency of the items; hence, the suitability of the questionnaire for use (Sekaran, 2005).

The six-item identification and compliance commitment section of the questionnaire was based on a 12-item questionnaire used by Bennett and Durkin (2000). They derived their questionnaire from the items that loaded most highly after factor analysis in a 21-item scale originally developed by O'Reilly and Chatman (1986). Three items each in this study measured identification and compliance commitment.

The responses were categorized into the nine management traits considered in the study, and statistical methods were used to analyze the collated data. The mean scores were plotted to represent the engineers' opinions about the nine traits in the study. The responses from the commitment questionnaire were also categorized and analyzed in the same manner. Descriptive statistics such as means and standard deviations were calculated from the data. Correlation analyses were performed to estimate the types and significance of correlations between managerial traits and engineers' commitment.

\section{Participants}

Participants in this study were Institute of Electrical and Electronics Engineers (IEEE) members who are design engineers, hardware engineers, and software engineers work in the Telecommunications Services and Telephone line of business. Apart from the basic criteria stated above, efforts were made to assure a diversified sample in terms of age, experience and educational background to help ensure the potential application scope of the research. Fifty-seven participants took part in this study.

\section{Procedures}

A questionnaire was administered to each participant via regular mail. The questionnaire asked questions about the nine different traits considered in this study. The questionnaire consisted of 39 questions on a five-point Likert-type scale.

\section{Data Processing}

Once the survey was completed, the results were collated by age, gender, position, years of experience and educational background. The responses were categorized into the following nine management traits: accountability, communication skills, courage, expertise, integrity, intellect, persistence, team building and vision. The mean scores were plotted to represent the engineers' opinions about the nine managerial traits previously defined in the study. The responses from the commitment questionnaire were also categorized in the same manner.

Correlation analysis was performed to investigate the relationship between aggregate trait mean scores and the commitment dimensions. Same procedure was also used between pairs of commitment dimensions. Pearson Product-Moment Correlation Coefficient ( $r$ ) was used for this purpose.

\section{Results}

Out of the 57 valid responses received, 49 respondents were male, while eight of them were female. Majority of the respondents (47) were 33 years or older, with the remaining 10 respondents younger than 33 years of age.

Most of the respondents (40) held graduate degrees, while 11 of them had four-year degrees. Six respondents did not have a bachelor's degree. 
With regard to length of service within the organization, 39 respondents had been with the same organization for less than 6 years, 12 respondents for 6 to 10 years, and six respondents for more than 10 years.

With reference to years of experience as an engineer, 29 respondents had 10-19 years, 16 respondents had 20 or more years, and 12 had less than 10 years of engineering experience.

The results revealed moderate positive correlations between aggregate management trait scores and identification commitment $(r=0.64)$, and between identification commitment and compliant commitment $(r=0.55)$; both were significant at .01 level. Moderate negative correlations were found, at .01 level of statistical significance, between management traits and intention to leave ( $r$ $=-0.55)$, and identification commitment and intention to leave $(r=-0.65)$. Table 1 shows the summary correlation table.

Table 1: Summary of Correlation among Parameters

\begin{tabular}{llllll}
\hline & & $\begin{array}{l}\text { Aggre- } \\
\text { gate trait }\end{array}$ & $\begin{array}{l}\text { Identification } \\
\text { commitment }\end{array}$ & $\begin{array}{l}\text { Compliance } \\
\text { commitment }\end{array}$ & $\begin{array}{l}\text { Intent to } \\
\text { leave }\end{array}$ \\
\hline $\begin{array}{l}\text { Aggregate } \\
\text { trait }\end{array}$ & Pearson correlation & 1 & $0.64\left(^{* *}\right)$ & 0.23 & $-0.55\left(^{* *}\right)$ \\
& Significance (2-tailed) & 0.000 & 0.087 & 0.000 \\
$\begin{array}{l}\text { Identification } \\
\text { commitment }\end{array}$ & Pearson correlation & 1 & $0.55\left(^{* *}\right)$ & $-0.65\left(^{* *}\right)$ \\
& Significance (2-tailed) & & 0.000 & 0.000 \\
$\begin{array}{l}\text { Compliance } \\
\text { commitment }\end{array}$ & Pearson correlation & & 1 & $-0.28\left(^{*}\right)$ \\
& Significance (2-tailed) & & & 0.037 \\
$\begin{array}{l}\text { Intent to } \\
\text { leave }\end{array}$ & Pearson correlation & & & 1 \\
\hline
\end{tabular}

* Correlation is significant at the 0.05 level (2-tailed).

** Correlation is significant at the 0.01 level (2-tailed).

\section{Discussion}

The value of $r$ for identification commitment (0.64) indicates a moderate positive correlation between perceived management traits and identification commitment. This result supports the first research hypothesis. The result is not surprising since identification commitment construct represents attitudes and behaviors that are adopted in order to gain association with a valued third party. If engineers have good experiences with their management, they are likely to develop a desire for identification with the organization, because managers are typically the primary link between engineers and the organization as an entity. 
Compliance commitment has little or no correlation with management traits $(r=0.23)$. This is contrary to the research hypothesis, which proposed a negative correlation between the two. This result points to the possibility of management traits being a non-factor as far as compliance commitment is concerned. Therefore, the second hypothesis is rejected.

In support of the third hypothesis, intent to leave was found to be negatively correlated with management traits $(r=-0.55)$. This moderate negative correlation is a very logical result, as engineers whose managers exhibit high management traits will most likely want to remain with their current organization. While other factors and their interactions might militate against their staying with the company, management traits still made strong impact on intention to leave.

\section{Commitment Dimension Relationships}

The value of $r$ for the relationship between identification commitment and intent to leave is -0.65 at .01 levels of statistical significance, which shows moderate negative correlation between the two. This implies that respondents with higher levels of identification commitment have lower intention to leave their respective companies. This relationship should be expected because those who have identified with the values of the company should have little or no reason to leave.

For the relationship between compliance commitment and intent to leave, the value of $r$ is -0.28 , with a statistical significance level of .05 . This shows low to moderate negative correlation. This implies that there is little or no relationship between compliance commitment and respondents' intent to leave.

For the identification commitment versus compliance commitment relationship, the value for $r$ is 0.55 , which is statistically significant at the .01 confidence level. This indicates moderate positive correlation between the two commitment dimensions. The results indicate that respondents with a higher identification commitment also are likely to possess a stronger compliance commitment. This finding seems to contradict previous research results reported by Durkin and Bennett (1999) and Bennett and Durkin (2000). This discrepancy might be a result of the current flux in the IT industry. Engineers with high identification commitment seemed to maintain their perception while being increasingly frustrated by their unstable industry.

\section{Conclusion}

This research explored management traits of engineering managers and their association with the commitment of engineers in the IT industry. Nine management traits and three commitment dimensions were defined for the study.

The results of the present study showed some significant correlations between management traits and the commitment of engineers to their employing organizations. The research also found that engineers with higher levels of identification commitment have lower intent to leave their respective companies. Those with higher identification commitment were also found to show higher levels of compliance commitment. A statistically significant relationship between compliance commitment and intent to leave could not be established.

The result of this study is expected to pave the way for further studies in IT engineer retention. It is also expected to allow organizations to focus on developing engineering managerial skills that are positively correlated with employee commitment. A concomitant potential benefit could also be to encourage engineers wishing to transition into management to start preparing themselves for the journey through acquiring and practicing the key managerial skills.

Future work should include engineers in areas other than the telecommunications group, expanding the commitment dimensions, and exploring other management traits. Ongoing studies should also be carried out, as the dynamics of the market change. 


\section{References}

1000ventures. (n.d.). The GE Leadership Effectiveness Survey (LES). Retrieved June 28, 2004, from http://www.1000ventures.com/business_guide/crosscuttings/tests_leadership_ef_byge.html

Bennett, H., \& Durkin, M. (2000). The effects of organisational change on employee psychological attachment. Journal of Managerial Psychology, 15(2), 126-147.

Bigliardi, B., Petroni, A., \& Dormio, A. I. (2005). Organizational socialization career aspirations and turnover intentions among design engineers. Leadership \& Organization Development Journal, 26(6), 424441.

Boehnke, K., DiStefano, A., DiStefano, J. J., \& Bontis, N. (1999). Leadership for extraordinary performance. IEEE Engineering Management Review, 27(1), 32-37.

Buchanan, B. (1974). Building organization commitment: The socialization of managers in work organizations. Administrative Science Quarterly, 19(3), 533-546.

Cohen, A., \& Golan, R. (2007). Predicting absenteeism and turnover intentions by past absenteeism and work attitudes: An empirical examination of female employees in long term nursing care facilities. $\mathrm{Ca}$ reer Development International, 12(5), 416 - 432.

Champy, J. (1995). Reengineering Management. New York: Harper Collins.

DeMarco, T., \& Lister, T. (1999). Peopleware: Productive projects and teams (2nd ed.). New York: Dorset House Publishing.

Durkin, M., \& Bennett, H. (1999). Employee commitment in retail banking: identifying and exploring hidden dangers. The International Journal of Bank Marketing, 17(3), 124-135.

Farris, G. F., \& Cordero, R. (2002). Leading your scientists and engineers 2002. Research Technolog Management, 45(6), 13-25.

Hunter, M. (2004). Teaming with talent. Supply Management, 9(17), 34-35

James, G. (1996). Business wisdom of the electronic elite. New York: Random House.

Kouzes, J. M., \& Posner, B. Z. (1995). The leadership challenge. San Francisco: Josey Bass.

Kerber, K. W., \& Buono, F. (2004). Leadership challenges in global virtual teams: Lessons from the field. S. A. M. Advanced Management Journal, 69(4), 4-10.

Lee, J., Huynh, M., Kwok, R., \& Pi, S. (2003), IT outsourcing evolution: past, present, future. Communications of the $A C M, 46(5), 84$.

Lynch, P. D., Eisenberger, R., \& Armeli, S. (1999). Perceived organizational support: Inferior versus superior performance by wary employees. Journal of Applied Psychology, 54(4), 467-483.

Mateas, R. C., \& Kleiner, B. H. (1999). Managing human behaviour in the information technology industry. Management Research News, 22(2/3), 27-31.

Matthews, J. (2004). The rise of the virtual company. Supply Management, 9(15), 32-33.

Morris, T., Lydka, H., \& O’Creevy, F. (1993). Can commitment be managed? Human Resource Management Journal, 3(3), 21-42.

O’Reilly, C., \& Chatman, J. (1986). Organizational commitment and psychological attachment: The effects of compliance, identification and internalization on pro-social behavior. Journal of Applied Psychology, $71(3), 492-499$.

Oni, O. O. (2005). Identifying and addressing the effect of management traits on the commitment of information technology engineers (Doctoral dissertation, Northcentral University, Prescott, AZ). Dissertation Abstracts International, 66 (07), A2641

Park, J. S., \& Kim, T. H. (2009). Do types of organizational culture matter in nurse job satisfaction and turnover intentions? Leadership in Health Services, 22(1), 20 - 38. 
Parker. G. (2003). Leading a team of strangers. $T+D, 57(2), 21-23$.

Porter, L., Steers, R., Mowday, R., \& Boulian, P. (1974). Organizational commitment, job satisfaction and turnover among psychiatric technicians. Journal of Psychology, 59(1), 603-609.

Purani, K. \& Sahadev, S. (2008). The moderating role of industrial experience in the job satisfaction, intention to leave relationship: An empirical study among salesmen in India, Journal of Business \& Industrial Marketing, 23(7), 475 -485.

Rifkin, K. I., Fineman, M., \& Ruhnke, C. H. (1999). Developing technical managers - First you need a competency model. Research Technology Management, 42(2), 53 -57.

Sekaran, U. (2005). Research methods for business: A skill-building approach (4th ed.). New York: John Wiley \& Sons.

Taylor, G., Dahnke, K., Snyder, L., \& Kuether, G. (1996). The recipe for a successful R\&D team. Chemtech, 26(5), 7-10.

Toscano, L., \& Waddell, J. (2003). Business transformation outsourcing. Public Utilities Fortnightly, 4(2), 30-33.

Trent, R. J. (1996). Understanding and evaluating cross-functional sourcing team leadership. International Journal of Purchasing and Materials Management, 32(4), 29-36.

Ulrich, D. (1997). Measuring human resources: An overview of practice and a prescription for results. Human Resource Management, 36(3), 303-320.

\section{Biography}

Oludotun Oni, PhD, is Professor of Information Systems at the University of Phoenix, USA. He obtained his doctorate degree in Information Systems from Northcentral University, USA. He was a pioneer lecturer of Mechanical Engineering at the Ondo State University (now University of Ado-Ekiti), Nigeria and later served as acting chair in 1993. He has been affiliated with the University of Phoenix since 2002, where serves as chair/supervisor on several doctoral dissertation committees at the School of Advanced Studies. By virtue of his credentials, which includes an M.Sc. degree in Engineering and experience spanning three continents and over 27 years, he is also able to teach a wide range of courses, including Advanced Computer Security, Computer Network Auditing, Contingency Planning and Disaster Recovery, Corporate Network Security, Applied Business Research and Statistics, and Healthcare Informatics. He represented the Information Systems discipline on the 12-member Faculty Council of the School of Business in 2009/2010 and won the prestigious "Outstanding Faculty Member of the Year Award" for the Southern California Campus in June 2010.

In order to maintain a balance between research and practice, he works in the telecommunications industry and serves as an adjunct professor and visiting scholar at two other universities. Many of his works focus on designing and delivering cutting-edge technical and business solutions on a global scale. Author of several practice tests in the IT certification industry (mainly on IP telephony design, troubleshooting and unified messaging), he sits on the advisory board of a global independent research firm. He is a member of various international professional bodies and a holds several professional certifications, including the Certified Information Systems Security Professional (CISSP). His current research interests are in the areas of ICT Management, wireless and mobile computing, information security and ICT policies in developing countries. He is currently editing a book on network security. 